\section{Tape for Microsectioning of Very Large, Hard or Brittle Specimens}

DURING the last decades of the nineteenth century several methods were introduced to make sectioning possible of such hard or brittle specimens as eggs, containing large amounts of yolk granules, and arthropods with a skeleton of chitin, where the usual paraffin technique failed.

The section-surface of the paraffin block was coated with a thin film of collodion, paraffin, shellac or mastic, and this procedure was repeated after each section made.

Sometimes such methods are still used, in case of emergency; but they are rather difficult to handle and very often quite unsatisfactory.

Against these methods a ribbon of cellulose tape applied over and firmly pressed to the section surface of a paraffin block or of a specimen in the freezing microtome serves admirably for the purpose.

The section is very firmly attached to the sticky substance of the tape, and hence it cannot be wrinkled or shattered by the sectioning. Sections ranging from one micron or less in thickness to several hundred microns are always quite even. In fact, there is no trouble at all in sectioning specimens from which it would seem to be impossible to get useful sections with any other method. (For example, with the tape method whole adult mice have been sectioned (for autoradiograms) in a freezing microtome without fixation or decalcification.)

The sticky substance on the tape is soluble in benzene, toluene and xylene. Hence, the paraffin (of paraffin sections attached to tape) cannot be dissolved in the usual manner in benzene. However, the paraffin can be slowly removed in warm amyl alcohol, the sticky substance being insoluble in alcohols.

The cellulose tape is stainable, therefore drops of stain solutions should be applied to the section only. Glycerol can be used as mounting medium.

However, from a histological point of view it is preferable to transfer the section to a glass slide by the following technique.

(1) Mount the section on the tape, with the section turned upwards, on a glass slide with small strips of tape (applied so that they do not cover any part of the section itself). This is in order to get the section on a horizontal level.

(2) Spread out, using a glass rod, $\frac{1}{2}$ per cent solution of celloidin in absolute alcohol and ether, equal parts, to a thin layer all over the section (but not all over the tape). Let the celloidin film perfectly dry in the air.

(3) Transfer the preparation to benzene (or toluene or xylene) in a shallow wide glass dish (for example, a Petri dish) and leave it until (within a few minutes) the collodion film, including the section, can easily be loasened from the tape. Leave the section for a while in benzene, so that all the remaining sticky substance is dissolved.

(4) Smear a cleaned slide rather liberally with egg albumen all over, dip the slide, with the smeared surface upwards, in the benzene and float the section, the previous 'tape-side' down, to the slide. Mount the section on the slide and press and blot it dry with a piece of filter paper.

(5) Transfer, at once, the slide to absolute alcohol and ether in equal parts, and leave it until the collodion is dissolved. In my experience the section is now firmly cemented to the slide.
(6) Transfer the slide to 95 per cent alcohol. Now the section can be treated as an ordinary deparaffinized section fixed on a glass slide, thus suitably stained and finally mounted in the usual manner.

Frozen sections fixed on tape must either be dried (for example, for autoradiograms of water-soluble radioactive substances) or, from a histological point of view, better, of course, be transferred from water to alcohol and to absolute alcohol before the collodion film is applied as described above.

The section can (for photographic registration of radioactivity) be attached directly to the photographic film without egg albumen, but preferably after moistening the film.

The tape method may be useful whenever the ordinary micro-sectioning technique fails and also for cutting very thin sections and for reconstructions. Sections made with the tape technique are even and are uniform from the beginning and never require any deforming treatment.

Series of sections can be made by cutting sections, border to border, on one and the same ribbon of tape, which is held rolled up on each side of the paraffin block above the level of the microtome knife during the sectioning, so that the knife does not cut the tape itself.

\section{Axel Palmgren}

Department of Anatomy and Histology,

Royal Veterinary College,

Experimentalfältet, Sweden. Feb. 20.

\section{Zoological Nomenclature}

Notice is hereby given that, as from November 11 , 1954, the International Commission on Zoological Nomenclature will start to vote on the following cases involving the possible use of its plenary powers for the purposes specified against each entry. Full particulars of these cases were published on May 11, 1954, in the Bulletin of Zoological Nomenclature in Parts 6, 7 and 8 of Volume 9. (1) immigrans Sturtevant, 1921 (Drosophila) (Cl. Insecta, Order Diptera), validation of ; (2) pruni Geoffroy, 1762 (Aphis) (CI. Insecta, Order Hemiptera), validation of ; (3) Lachnus Burmeister, 1835, and Cinara Westwood, 1835 (Cl. Insecta, Order Hemiptera), designation of type species for; (4) Stentor Oken, 1815 (Cl. Ciliophera), validation of, and designation of type species for ; (5) Melanargia Meigen, 1828 (Cl. Insecta, Order Lepidoptera), validation of ; (6) Geoffroy, 1762, Hist. abrégée; validation of six generic names (Stratiomys, Stomoxys, Volucella, Nemotelus, Scatopse, Bibio) in the Order Diptera, published in; (7) Palmatotriton Smith, 1945 (Cl. Amphibia), suppression of ; (8) Ammonites mammillatus Schlotheim, 1813, designation of neotype for, and Douvilleiceras de Grossouvre, 1893, designation of type species for (Cl. Cephalopoda, Order Ammonoidea).

Comments on the above cases should be sent to me as soon as possible.

Francis Hemming

(Secretary to the International Commission on Zoological Nomenclature)

28 Park Village East,

Regent's Park,

London, N.W.I. 